\title{
Prevalence of auditory changes in newborns in a teaching hospital
}

\section{Prevalência de alterações auditivas em recém-nascidos em hospital escola}

\author{
Valeriana de Castro Guimarães', Maria Alves Barbosa². \\ 1) Epidemiologist. Doctor in Sciences of the Health. Responsible for the Service of Audiology of the Clinic of Otolaryngology HC/UFG. \\ 2) Doctor in Nursing. Head Professor of the College of Nursing - UFG. \\ Institution: Hospital of the Clinics of the Federal University of Goias. \\ Goiania/GO - Brazil. \\ Mailing address: Valeriana de Castro Guimarães - Hospital of the Clinics of the Federal University of Goias - Primeira Avenida - Clinic of Otolaryngology - University \\ Sector-Goiania/GO - Brazil - Zip-code: 74605-020. - E-mail: valerianacastroguimaraes@gmail.com \\ Article received in June 20, 2011. Article approved in August 14, 2011.
}

\section{SUMMARY}

Introduction: The precocious diagnosis and the intervention in the deafness are of basic importance in the infantile development. The loss auditory and more prevalent than other joined riots to the birth.

Objective: Esteem the prevalence of auditory alterations in just-born in a hospital school.

Method: Prospective transversal study that evaluated 226 justbeen born, been born in a public hospital, between May of 2008 the May of 2009.

Results: Of the 226 screened, 46 (20.4\%) had presented absence of emissions, having been directed for the second emission. Of the $26(56.5 \%)$ children who had appeared in the retest, 8 (30.8\%) had remained with absence and had been directed to the Otolaryngologist. Five (55.5\%) had appeared and had been examined by the doctor. Of these, 3 (75.0\%) had presented normal otoscopy, being directed for evaluation of the Evoked Potential Auditory of Brainstem (PEATE). Of the total of studied children, 198 (87.6\%) had had presence of emissions in one of the tests and, $2(0.9 \%)$ with deafness diagnosis.

Conclusion: The prevalence of auditory alterations in the studied population was of $0,9 \%$. The study it offers given excellent epidemiologists and it presents the first report on the subject, supplying resulted preliminary future implantation and development of a program of neonatal auditory selection.

Keyword: precocious diagnosis, auditory loss, deafness, neonatal selection.

\section{RESUMO}

Introdução: O diagnóstico e a intervenção precoces na surdez são de fundamental importância no desenvolvimento infantil. A perda auditiva e mais prevalente que outros distúrbios encontrados ao nascimento.

Objetivo: Estimar a prevalência de alterações auditivas em recém-nascidos em um hospital escola.

Método: Estudo transversal prospectivo que avaliou 226 recém-nascidos, nascidos em um hospital público, entre maio de 2008 a maio de 2009.

Resultados: Dos 226 triados, 46 (20,4\%) apresentaram ausência de emissões, sendo encaminhados para a segunda emissão. Das $26(56,5 \%)$ crianças que compareceram no reteste, 8 $(30,8 \%)$ permaneceram com ausência e foram encaminhadas ao otorrinolaringologista. Cinco $(55,5 \%)$ compareceram e foram examinadas pelo médico. Destas, $3(75,0 \%)$ apresentaram otoscopia normal, sendo encaminhadas para avaliação do Potencial Evocado Auditivo de Tronco Encefálico (PEATE). Do total de crianças estudadas, $198(87,6 \%)$ tiveram presença de emissões em um dos testes e, 2 (0,9\%) com diagnóstico de surdez.

Conclusão: A prevalência de alterações auditivas na população estudada foi de 0,9\%. O estudo oferece dados epidemiológicos relevantes e apresenta o primeiro relatório sobre o tema, fornecendo resultados preliminares para futura implantação e desenvolvimento de um programa de triagem auditiva neonatal.

Palavras-chave: diagnóstico precoce, perda auditiva, surdez, triagem neonatal. 


\section{INTRODUCTION}

The concern with the hearing grows to each day, a time that the infantile deafness is considered a problem of public health. The illness attacks of one the three healthful neonates in each 1,000 births and approximately two the four in 1.000 babies of risk. The deafness is disease more prevalent (30: 10.000) related to the birth, when compared with other diseases as, for example, those detected with the heel prick, phenylketonuria (1: 10.000); falciform anemia (2: 10.000); hypothyroidism $(2,5: 10.000)(1,2,3,4,5)$.

In defense of the precocious detention of the auditory alterations, some programs of neonatal auditory selection had been developed. The American Academy of Pediatrics (1999) and the Joint Committee on Infant Hearing (2000) suggest that the Programs of Hearing Screening Neonatal (PTAN) carry through objective evaluation for electrophysiological measure, using the EOA and/orEvoked Potential Auditory of Brainstem (PEATE) $(4,6,7)$. However, the examination of the PEATE presents high cost and demand much time for its application. Moreover, by needing personal specialized, it is not recommended as method of first line in the universal selection, although to be used in the evaluation of situations identified for other methods (3).

The examination of Transient Evoked Otoacoustic Emission (EOAT) comes being widely used in everybody. The application most promising of the evoked emissions mentions its use to it as device of selection for the identification of auditory deficiency, especially in just-been born and suckling existing in the whole world. The examination of the EOAT is of easy use, objective, not invasive, fast, of low cost, makes possible the selection of a great number of children and is observed in almost all the normal ears $(1,2,8)$.

The evoked otoacoustic emissions are caught sonorous energies of low intensity in the external acoustic meatus in reply to a sonorous stimulation. The procedure does not offer damages, risks, discomfort; it is fast, painless, with high sensitivity and specificities to detect auditory alterations $(1,2)$.

From this perspective, this study has for objective esteems the prevalence of auditory alterations in just-born in a hospital school.

\section{METHOD}

After approval in a Committee of Ethics of a university hospital, initiated the present study. One is about a study of carried through prospective transversal delineation in the maternity of the hospital in the CenterWest of Brazil, the period of May of 2008 to May of 2009.

The population of reference for the present study, enclosed the just-been born ones that they had appeared for selection between May of 2008 to May of 2009.

The collection of data occurred in the service of audiology of the hospital, where the responsible mother or answered to one anamneses, that she approached given relative to the health in the gestational and neonatal period, beyond spoon information on the presence or not of the pointers of risk for the deafness.

It had been enclosed, in the sampling, children born in the maternity, of both the gender, whose responsible they had agreed to participating of the study, signing the Term of Free Assent and Clarified (TCLE). It was adopted as exclusion criteria the born just-been born ones in other units of health and/or it are of the period of comprehensiveness of the study, as well as those whose responsible they had not agreed to participating of the research.

The study it considered as changeable, the sex, gestational age and the presence of pointers of risk for deafness, that as Joint Committee on Infant Hearing (2000) encompass: neonates that are more than 48 hours in the neonatal UTI; malformation of head and neck; syndromes associates the auditory alterations; familiar history of congenital auditory deficiency; neonates infections such as toxoplasmosis, syphilis, cytomegalovirus congenital, herpes and rubella (Storch) (6).

At the high moment of the hospital one of the mother and the just-been born one, the mother was lead to the Sector of Phonoaudiology set appointments one day for the auditory selection of its son. The examinations had been set appointments for ambulatory evaluation during the first month of life of the child. The selections had been offered a time per week, in the fridays.

For the evaluation of the cochlear function was used a device of transient otoacoustic emissions (EOAT) Capella (Madsen) hardwired to a portable microcomputer. During natural sleep or after breast-feeding, the sounding lead for capitation of the emissions was connected in the external auditory conduit of the just-been born one. In agreement, with the anatomical distribution of the frequencies in the cochlea it was considered, as criteria of normality, presence of reply in three of the five bands of frequency, relation level signal/the 6 equal or superior noise dBNPS (decibel Sound pressure level) in the frequencies of 2,3 and $4 \mathrm{KHz}$ and equal or superior reproducibility $50 \%$, as well as 
relation signal/the 3 equal or superior noise dBNPS and equal or superior reproducibility $50 \%$ in the frequencies of 1 and 1,5 KHz.

In case that the examination presented modified in the first selection, one second selection was carried through 15 days after the first EOAT. In the second selection, as well as in the first one, a new evaluation of the EOAT was carried through. In the cases where as the examination he remained modified, the children had been directed to the otolaryngologist doctor. In this stage, the children, in which the otoscopy met normal, had been lead the phase of the inquiry, and directed to the accomplishment of the PEATE examination $(9,10)$. The children with alterations otoscopic hadbeen treated and later submitted to the third examination of EOAT.

The size of the sample was esteem on the basis of the main objective of this work. For the calculation of the sample size the test of sampling of the ratio for finite samples was used. Considering the error of $5 \%$, through this test, a sample of 220,6 was gotten just-been born and had been enclosed in this study 226 children.

The collected data had been organized in electronic spread sheet of the Excel for posterior analysis in Statistical Package for Social Science SPSS version 17.0. In the analysis statistics test of Fisher in substitution to the Qui-square in tables was used where if they related the gender (masculine and feminine) with the reply absence. For conclusion how much to the test, the reliable level of $95 \%$ was fixed, that is, significant $p<0,05$.

\section{RESULTS}

In the chance where the study it was developed, the hospital unit not had device for the accomplishment of the EOAT examination. Of this form, the device used during the research belonged to a particular clinic, being available only one time per week. In the period of the computed study 764 had been born livings in the maternity in study. Soon, the responsible ones for the just-been born ones had been invited to participating of the research in question.

The 226 just-been born that they had appeared the selection had been tested by means of the test of EOAT, being $113(50 \%)$ of masculine sex and $113(50 \%)$ of the feminine one. The age varied of one day the eight months. The age varied to 1 day to 8 months, 60 (26.5\%) had been born daily pay-term, 165 (73.0\%) the term and $1(0.5 \%)$ after-term.

In the first evaluation of the just-been born ones that had presented presence of emissions, 86 (48\%) were of masculine sex and 93 (52\%) of the feminine sex. In the cases of reply absence, 13 (27.7\%) of the masculine sex had presented unilateral absence and $16(34.0 \%)$ bilateral . In relation to the feminine sex, 8 (17.0\%) had presented unilateral absence and 10 (21.3\%) bilateral. It is observed that it did not have significant difference in relation to the sex and the imperfection ( $p=0,237)$, as evidenced in Table 1.

Of the 226 just-been born taken care of, 46 (20.4\%) had presented absence of emissions and had been directed for the second evaluation. A child, due to more advanced age ( 8 months) was directed directly to the otolaryngologist doctor. Of those, 26 (56.5\%) had appeared and 20 (43.5\%) had not appeared to the retest.

Of the total of children evaluated in as the examination, $18(69.2 \%)$ had presented presence of emissions, and $8(30.8 \%)$ had remained with absence. Of the 8 children, 7 (27.0\%) had presented bilateral absence and 1 (3.8\%) unilateral one (right ear), 6 (75.0\%) children were of masculine sex and 2 (25.0\%) of the feminine one. One notices that it did not have difference in relation to the sex and the imperfection in second evaluation EOA ( $\mathrm{p}=$ $0,750)$ as it demonstrates Table 2.

Of the 9 children directed for medical evaluation, 5 (55.5\%) had appeared and had been examined by the otolaryngologist. Of these, 3 (75.0\%) had presented normal otoscopy and had been directed for PEATE examination and $2(66.7 \%)$ had alterations to the otoscopy (cork of earwax and serous otitis). Excessively, 4 (44.5\%), had not appeared to the consultation.

Table I. Absence in the first auditory selection as alteration I joined or bilateral. HC-UFG/ 2010.

\begin{tabular}{lcccccc}
\hline FirstEOA & \multicolumn{2}{c}{ Male } & \multicolumn{2}{c}{ Female } & \multicolumn{2}{c}{ Total } \\
& $N$ & $\%$ & $N$ & $\%$ & $N$ & $\%$ \\
\hline Unilateralabsence & 13 & 27,7 & 8 & 17,0 & 21 & 44,7 \\
Bilateralabsence & 16 & 34,0 & 10 & 21,3 & 26 & 55,3 \\
\hline Total & 29 & 61,7 & 18 & 38,3 & 47 & 100,0
\end{tabular}

Fisher Test: $\mathbf{p}=0,237$

Table 2. Absence in the second auditoryselection as alteration I joined or bilateral. HC-UFG/ 2010.

\begin{tabular}{lcccccc}
\hline SecondEOA & \multicolumn{2}{c}{ Male } & \multicolumn{3}{c}{ FemaleTotal } \\
& $N$ & $\%$ & $N$ & $\%$ & $N$ & $\%$ \\
\hline Unilateralabsence & $\mathrm{I}$ & 12,5 & - & 0,0 & $\mathrm{I}$ & 12,5 \\
Bilateralabsence & 5 & 62,5 & 2 & 25,0 & 7 & 87,5 \\
\hline Total & 6 & 75,0 & 2 & 25,0 & 8 & 100,0
\end{tabular}

Fisher Test: $\mathrm{p}=0,750$ 
Three children had been directed for evaluation with the PEATE. Two had appeared to the examination, and had presented abnormality in the results, confirming the deafness presence. The responsible for the children had been guided and directed (with reports) for acquisition of Personal Hearing Amplification Device (AASI) and rehabilitation.

In the studied sample (226), 61 (27.0\%) just-been born had presented pointers of risk for deafness. The found pointers more during anamneses had been: 47 (20.8\%), neonates with bigger permanence that 48 hours in the neonatal UTI, familiar history of congenital auditory deficiency in 8 children (3.5\%), 4 (1.8\%) with some congenital infection (syphilis, toxoplasmosis, rubella, cytomegalovirus, herpes) and 2 (0.9\%) with Syndromes not necessarily associates the auditory alterations, what it can be observed in Chart 1.

\section{DISCUSSION}

Although to be the ideal, the accomplishment of the examination before the hospital high one nor always is possible. In the maternity in study, the children receive high hospital between 36 and 48 hours of life. Data demonstrate that, in countries as the Ivory Coast the mothers and just-been born healthful the birth in public hospital or two days in particular net remains only one day after, what it becomes impracticable the selection during the internment (11). The same it does not occur in Greece, where the neonates after receive high 4 or 5 days after the birth (12).

In the present study, just-born $29.6 \%$ of the 764 had been submitted to the selection. This index of comprehensiveness was superior to evidenced 20\% in the South of Africa (13). Literature describes high values of comprehensiveness. However, one is about programs of TAN implanted has years in the searched units.

In the first evaluation, the index of children with normal hearing evaluated as deficient auditory, that is, the results false-positive in the first EOAT, was of $7,9 \%$. Superior results of false-positive had been observed by Matos et al. (16.9\%) (5). In the Côte d'Ivoire, the falsepositive tax was of $11,25 \%$ (11). As much in Saudi Arabia how much in Sicily the false-positive indices had presented inferior $2.3 \%$ and $0.74 \%$ respectively $(14,15)$. In Malaysia, the raised tax of failure (false-positive in about 15\% in the first test) is attributed to the fact of the test to have been carried through before 24-hour. In this age, the just-been born ones are more inclined to have residues in External Auditory Canal (CAE), that it intervenes with the capitation of the otoacoustic emissions (16). Authors consider that the
Chart I. Distribution of the factors of risk for deafness in relation to the results of the EOAT. HC-UFG/ 2010.

\begin{tabular}{lrcc}
\hline RiskFactors & $\mathrm{N}(\%)$ & \multicolumn{2}{c}{ First EOA } \\
& & Passed & Failed \\
\hline None & $165(73,0 \%)$ & 138 & 27 \\
UTI & $47(20,8 \%)$ & 31 & 16 \\
Malformation & $-(0,0 \%)$ & - & - \\
Syndromes & $2(0,9 \%)$ & 2 & - \\
HistoryDA & $8(3,5 \%)$ & 7 & 1 \\
Neonatalinfection(STORCH) & $4(1,8 \%)$ & 1 & 3 \\
\hline Total & $226(100,0 \%)$ & 179 & 47 \\
\hline
\end{tabular}

increased one of the age can promote an improvement in the index of presence of reply in the first EOAT and, consequently, a reduction in the false-positive tax $(8,17)$.

Of the 26 (56.5\%) children who had appeared for as the examination, 8 (30.8\%) had remained with negative test and had been directed for specialized medical evaluation. Similar index was evidenced in Saudi Arabia. In that country, of 1.043 just-been born examined in the second stage, 29\% had not had reply (15). Lesser failure rates had been observed in a study in the city of Ferrara where $2.05 \%$ had been disapproved in the second phase and had been evaluated in third (18). Superior failure rates had been observed in a research in Greece with 541 neonates that had repeated the test. Of these, 238 (44\%) had remained with absence of EOAT in the retest (12).

In the third stage of procedure established in this study, 9 children had been directed for otolaryngologic evaluation for presenting absence in the examination of emissions. Of the children who had appeared and had been examined by the specialist, 3 had presented normal otoscopy and had been directed for PEATE, 2 had presented otoscopicalterations, one with cork of earwax and another one with serous average otitis that, after treated, had been directed for the third examination of emissions. The child with average otitis, after to be treated, got presence of emissions in both the ears. To another child it did not appear to the test. Of this form, the high index of imperfection can be attributed to the number of children with otologic alterations observed by the otolaryngologic during the otoscopy. The secretion presence in the ear, in the first hours of life, can compromise the conduction of the sound causing absence in the emissions (19). In the state of the Espirito Santo $3(0.08 \%)$ children had presented alterations of average ear (8). In Greece, of the 238 (44\%) disapproved in second EOAT, 18 they had average otitis with effusion (12).

In the studied population (226 just-been born), the prevalence of auditory alterations was of $0,9 \%$ with estimate 
of 9:1.000. These data go to the meeting of the evidenced ones in a study carried through in Bauru. In that city, the authors had verified that of the 11,466 just-been born submitted to the auditory selection, 11 children had presented sensorineural auditory loss, a prevalence of 0,96\% (9). In the Cantabria, the incidence of congenital deafness was of 8,5 for each 1000 (10). In the Côte d'Ivoire, the prevalence of congenital auditory alteration was of 6 in 1.000 (11). Such prevalence are raised when compared with other finding in Milan and Ferrara, where the prevalence of congenital deafness in the population was esteem in $0,32 \%$ and $0,45 \%$ respectively $(18,20)$. In the South African continent 3 in each 1,000 children present deafness to the rising (13).

The literature describes the bilateral deafness as the most frequent. In Milan, for example, in the studied population, 63 children $(0.32 \%)$ had presented auditory loss, between which 33 had bilateral deafness (20). In Arabia, of the 22 children with deafness, 20 children had had bilateral sensorineural auditory loss (15). In this study, of three children who had been directed for inquiry for the PEATE examination, two (0.9\%) they had carried through the examination, whose resulted they had presented compatible electrophysiological with severe sensorineural auditory loss in an ear and deep degree in the ear counter-lateral.

Of the total of just-been born evaluated, 61 presented factors of risk for deafness, representing $27.0 \%$ of the sample. A child with deafness diagnosis presented familiar history of auditory deficiency as indicating of risk for deafness, while to another one did not present factor of associated risk. Similar data had been described for Lima et al. (19). Of the evaluated neonates, two had presented sensorineural auditory loss, both of the masculine sex. One of them has as reference the hereditary succession as risk factor.

In the studies carried through in two Brazilian maternities, $12.61 \%$ of the children were carrying of pointers of risk for deafness (8). In the population of two university hospitals, $29.92 \%$ and $12.5 \%$ of the respective samples presented at least a pointer of risk for auditory deficiency $(5,21)$. Of the 11,466 just-been born sorted in Bauru - SP, $11.20 \%$ had presented one or more factors of risk for auditory alterations (9).

In the present study, even so the two children with confirmed deafness were of the masculine sex, an association between the sex and the affected ear was not evidenced. Such fact occurred, as much in the first one how much in the second tests. These findings little differ from the observed ones in the research carried through in Saudi Arabia, where it did not have significant difference between girls and boys (15).
For the JCIH, the ideal it is that the diagnosis occurs before the three months of age and that the intervention is initiated by return of the six months (6). Corroborating with the goal established for the Committee, in the present study, the child appeared "It" for the first examination with 15 days of life, being prostetized before the 4 months of age. In the case of child " $\mathrm{B}$ ", the confirmation of the deafness occurred in skillful time (only 20 days after the first examination). However, the first emission occurred to the 8 months of age. In case that, the same one had carried through the EOAT in the first month of life, certainly, would have been prostetized in the time praised for the JCIH (6). Differently, in the Espirito Santo the age of diagnosis was of four months and way and the system of amplification acquired to the 11 months the age (8). In the Nigerian, the average of age of diagnosis of the loss of the hearing was of, approximately, 8 months (22). Currently, the two children with deafness confirmed meet prostetized and inserted in whitewashing programs.

In the studied population, $11.5 \%(26 / 226)$ of the children had inconclusive diagnosis; therefore they had not appeared to the pursuing. Difficulties similar were faced in research carried through in the Nigerian, where $10 \%$ of the children had not concluded the diagnosis (22). High values had been described in Malaysia and Ivory Coast, where $35 \%$ and $81.25 \%$ of the children had not returned for diagnosis $(11,16)$. The lack of sensitization of the country how much to the importance of the precocious identification of the auditory loss it intervenes with the pursuing, a time who are they them responsible right-handers for the child (13).

The precocious diagnosis has been each emphasized time more, a time that the detention of the deafness before the three months of age and the intervention before the six favor a development in the deaf child next to the one to the children listeners (3).

The auditory privation, in general way, affects the quality of life of the child, therefore it compromises the acquisition of the language, cognitive, educational, psychological and social the aspects. Thus, the first step to minimize the upheavals caused for the deafness is, without a doubt, the precocious identification and intervention of the illness, being necessary the involvement and awareness of all the professionals of health and the family.

The limitations of the study, it is cited difficulty in collecting the data and, some factors is involved in this process, between them the lack of adhesion to the test, that can be attributed to the fact of the researchers to available the examination only in the fridays. For this reasons, the selection could not be carried through daily, or before, of high the hospital one. Another observed important 
factor was not the involvement of the parents in the evaluations that can have been influenced for the disinterest produced for the unfamiliarity on the deafness, for the unreliability and distrust in relation to the result, or for diverse reasons, which are not part of the objectives of the present study.

Measures as to available the accomplishment of the examination every day of the week could reduce the possibility of abandonment to the test. However, during the research it had facility in the access to the medical specialist, as well as the o examination of PEATE, necessary for diagnosis of the auditory deficiency. The presented data can contribute in the direction to supply to subsidies the future analyses on the thematic one in the region.

\section{CONCLUSION}

Of the 226 just-been born evaluated, 2 (0.9\%) had had the diagnosis of confirmed deafness. Thus, the prevalence of auditory alterations in the studied population was of 0,9\% with estimate of 9:1000 born alive.

In a city without real information on the just-born prevalence of auditory loss, the current study it offers given excellent epidemiologists for public health e, presents the first report on the subject, supplying resulted preliminary future implantation and development of a program of neonatal auditory selection in the institution.

\section{BibliogRAPHIC REFERENCES}

1. Frasson AM. Emissões Otoacústicas. In: Figueiredo MS. Conhecimentos essenciais para entender bem Emissões Otoacústicas e Bera. São José dos Campos: Pulos; 2003.

2. Guimarães VC, Barbosa MA. Avaliação auditiva no recémnascido e suas implicações éticas. Rev C S Col. 2010, 15(2):559-62.

3. Segre CAM. Prevalência de perda auditiva em recémnascidos de muito baixo pés. J Pediatr. 2003, 79(2):1034.

4. Grupo de Apoio a Triagem Auditiva Neonatal (Gatanu). Disponível em: http://www.gatanu.org/tan/ introducaoTAN.php. Acessado em 20 de junho de 2010

5. Mattos WM, Cardoso LF, Bissani C, Pinheiro MMC, Viveiros CM, Filho WC. Newborn hearing screening program implantation analysis at a university hospital. Rev Bras Otorrinolaringol. 2009, 75(2):237-44.
6. Joint Committee on Infant Hearing. Year 2000 Position Statement: Principles and Guidelines for Early Hearing Detection and Intervention Programs. Pediatrics. 2000, 106(4):798-817.

7. Comitê Brasileiro Sobre Perdas Auditivas na Infância. 1ª Recomendação - Período Neonatal. Recomendação 01/99. Jornal do CFFa. 2000; 5:3-7.

8. Barreira-Nielsen C, Neto HAF, Gattaz G. Processo de implantação de Programa de Saúde Auditiva em duas maternidades públicas. Rev Soc Bras Fonoaudiol. 2007, 12(2):99-105.

9. Bevilacqua MC, Alvarenga KF, Costa OA, Moret AL. The universal newborn hearing screening in Brazil: from identification to intervention. Int J Pediatr Otorhinolaryngol. 2010, 74(5):510-5.

10. González ALA, Bonilla MC, Morales AC, Gómez CF, Barrasa BJ. Cribado universal de la hipoacusia congénita en Cantabria: resultados de los dos primeros años. An Pediatr (Barc). 2005, 62(2):135-40.

11. Tanon-Anoh MJ, Sanogo-Gone D, Kouassi KB. Newborn hearing screening in a developing country: results of a pilot study in Abidjan, Côte divoire. Int J Pediatr Otorhinolaryngol. 2010, 74(2):188-91.

12. Korres S, Nikolopoulos TP, Peraki EE, Tsiakou M, Karakitsou M, Apostolopoulos N, Economides J, Balatsouras D, Ferekidis E. Outcomes and efficacy of newborn hearing screening: strengths and weaknesses (success or failure?). Laryngoscope. 2008, 118(7):1253-6.

13. SwanepoelD, Ebrahim S, Joseph A, Friedland PL. Newborn hearing screening in a South African private health care hospital. Int J Pediatr Otorhinolaryngol. 2007, 71(6):881-7.

14. Martines F, Porrello M, Ferrara M, Martines M, Martines E. Newborn hearing screening project using transient evoked otoacoustic emissions: Western Sicily experience. Int J Pediatr Otorhinolaryngol. 2007, 71(1):107-12.

15. Habib HS, Abdelgaffar H. Neonatal hearing screening with transient evoked otoacoustic emissions in Western Saudi Arabia. Int J Pediatr Otorhinolaryngol. 2005, 69(6):839-42.

16. Abdullah A, Hazim MY, Almyzan A, Jamilah AG, Roslin S, Ann MT, Borhan L, Sani A, Saim L, Boo NY. Newborn hearing screening: experience in a Malaysian hospital. Singapore Med J. 2006, 47(1):60-4.

17. Bansal S, Gupta A, Nagarkar A. Transient evoked otoacoustic emissions in hearing screening programs: 
protocol for developing countries. Int J Pediatr Otorhinolaryngol. 2008, 72(7):1059-63.

18. Ciorba A, Hatzopoulos S, Busi M, Guerrini P, Petruccelli J, Martini A. The universal newborn hearing screening program at the University Hospital of Ferrara: focus on costs and software solutions. Int J Pediatr Otorhinolaryngol. 2008, 72(6):807-16.

19. Lima MCMP, Rossi TRF, Françozo MFC, Marba ST, Lima GML, Santos MFC. Detecção de perdas auditivas em neonatos de um hospital público. Rev Soc Bras Fonoaudiol. 2010, 15(1):1-6.

20. Pastorino G, Sergi P, Mastrangelo M, Ravazzani P, Tognola G, Parazzini M, Mosca F, Pugni L, Grandori F. The Milan
Project: a newborn hearing screening programme. Acta Paediatr. 2005, 94(4):458-63.

21. Durante AS, Carvallo RMM, Costa MTZ, Cianciarullo MA, Voegels RL, Takahashi GM, Soares AVN, Spir EG. A implementação de programa de triagem auditiva neonatal universal em um hospital universitário brasileiro. Pediatria (São Paulo). 2004, 26(2):78-4.

22. Olusanya BO, Wirz SL, Luxon LM. Hospital-based universal newborn hearing screening for early detection of permanent congenital hearing loss in Lagos, Nigeria. Int J Pediatr Otorhinolaryngol. 2008, 72(7):991-1001. 